\title{
Integrating Basic Urban Services for Better Sanitation Outcomes
}

\author{
Rebecca Scott ${ }^{1, *} \mathbb{C}$, Pippa Scott ${ }^{2}$, Peter Hawkins ${ }^{3}$, Isabel Blackett ${ }^{3}$, Andrew Cotton ${ }^{4}$ and \\ Alix Lerebours ${ }^{1}$ \\ 1 School of Architecture, Building and Civil Engineering, Loughborough University, Loughborough \\ LE11 3TU, UK; a.m.lerebours@Lboro.ac.uk \\ 2 i-san LLP, Somerset BA3 5SU, UK; pippa.scott@i-san.co.uk \\ 3 Inclusive Sanitation in Practice, Norwich NR1 3NX, UK; phsanitation@gmail.com (P.H.); \\ isabel.blackett@pi2b.com (I.B.) \\ 4 Retired (formerly of Loughborough University), Loughborough LE11 3TU, UK; andrewpcotton@gmail.com \\ * Correspondence: r.e.scott@Lboro.ac.uk
}

Received: 2 October 2019; Accepted: 23 November 2019; Published: 27 November 2019

check for updates

\begin{abstract}
Rapid urbanization in developing countries demands better integration of planning and delivery of basic services if cities are to be sustainable, healthy and safe. Sanitation improvements are commonly overlooked as investments go towards more visible services such as water supplies and drainage networks. The Sustainable Development Goal for sanitation and hygiene currently remains severely off-track. This paper presents the findings of a Delphi method survey to identify expert consensus on both why and how to integrate sanitation, by which we mean both sewered and non-sewered sanitation services, into other basic urban services (including water supply, drainage, energy and roads) to achieve better sanitation and broader development outcomes, notably for poor citizens. Consensus on why integration is important highlights the physical interdependence of services, where neglect of one service can compromise gains from another investment or service. Consensus on how includes actions to address political priorities and leadership; governance and capacity constraints; clearer planning, procurement and financing mechanisms; and adopting incremental approaches matched to wider urban strategies. It was suggested that achieving these actions would improve accountability, monitoring and service level audits. Experience from previous integrated urban programmes should be incorporated into formulating new sanitation service agreements across all service types. Supported by better-informed dialogue and decision-making between those responsible for urban sanitation and for associated basic services, we suggest integrated and incremental approaches will enable more sustainable urban services planning to achieve 'quality of life' outcomes for poor urban residents.
\end{abstract}

Keywords: Accountability; Delphi; integrated; planning; sustainability; urban development

\section{Introduction}

Developments over the last decade have seen a diversity of technological and logistical solutions being applied to address the challenge of managing human waste in cities. Combining different non-sewered, on-site sanitation systems with sewerage is likely to provide a more appropriate and resilient solution for many growing global cities. A deepening global specialism of non-sewered systems has seen sanitation move programmatically, and in some cases institutionally, away from water. This may be for good reason, allowing for dedicated mandates and budget lines of an often-neglected sector. It, however, also risks a siloed approach to a fundamental aspect of public health engineering.

Despite renewed focus and increased investments in recent years, urban sanitation strategies and planning frameworks are not yet adequate to achieve the Sustainable Development Goal target (6.2) for 
adequate and equitable sanitation, in particular for the urban poor [1]. Global awareness of the extent to which sanitation was falling behind other development targets at the start of the 2000s in many cases led to increased coverage of access to stand-alone sanitation facilities. This has not necessarily been met with access to comprehensive safely managed sanitation services. Sanitation interventions that do not respond to urban complexity, or the dynamics of the household and peri-household urban environments, are not comprehensively addressing the problem [2]. A more recent call to action in the WASH (water, sanitation and hygiene) sector is for citywide inclusive sanitation (CWIS), whereby appropriate urban sanitation approaches and technologies for global cities are to be (re)integrated into urban development planning and implementation. The goal is to provide more tangible results for urban residents by 2030 [3]. Rees [4] observes that integrated management of resources to deliver water and sanitation services together, with institutional frameworks to enable appropriate division of roles and functions, are essential for responding to growing environmental pressures from rapid urbanization. The New Urban Agenda adopted by the United Nations in 2016 sets ambitious development objectives. However, it also recognizes that competing service improvements, weak planning controls and limited resources for inter-sectoral collaboration present significant barriers to local governments for achieving them [5]. Adopting a more integrated approach to basic urban services represents a significant policy shift with regards to sanitation. While there is an acknowledgement that further integration is desirable, the extent of consensus amongst expert researchers and practitioners around key issues of relevance, and insights into how change can best be achieved in practice, is not known.

The aim of this paper is to present the case for, and against, greater integration of urban sanitation services with other basic urban services (that may include water supply, drainage, solid waste disposal, energy and roads) and priority actions to achieve this. It does so through presenting the results of research that aimed to identify expert consensus around agreed arguments and priority actions to enable greater integration between basic urban services. Based on the results of a Delphi expert consensus survey, collectively these actions are considered to also support the achievement of better sanitation outcomes and wider impacts from urban development.

\section{Materials and Methods}

This paper is the result of a two-stage research process. The first consisted of a literature review focused around case studies identified by the authors, plus literature considering the wider challenges of service integration and urban sanitation. This produced a position statement articulating the foundational concepts underpinning arguments for, and against, the latest thinking in urban sanitation discourse [3]. The second stage of the research process was a Delphi survey which sought to gain further expert opinion to support, or challenge, the initial position statement and arguments, and to test consensus on both why and how to integrate sanitation better into urban development planning.

\subsection{Developing the Position Statement}

To develop the position statement, the fundamental dimensions of urban sanitation development discourse that underpin this study were considered. Urban sanitation in this paper refers to the overall delivery of sanitation services, including both non-sewered and sewered sanitation systems, noting that on a global scale the vast majority of sanitation services are non-sewered. What is presented below is not a comprehensive overview of urban development and urban sanitation literature, rather content which articulates the main concepts underpinning the study, notably around the rationale for why the integration of urban sanitation with other basic services.

\subsubsection{The Rationale for Integrated Urban Services for Improved Sanitation}

Achieving healthy living conditions in cities is a requirement for city planners and authorities to attain the Sustainable Development Goals, including those for clean water and sanitation, good health and wellbeing, sustainable cities and reduced inequalities [1]. Unplanned city developments can result in marginalized communities, environmental degradation, reduced health and effective workdays, 
and lower quality of life [6-8]. While recognizing the scale of such challenges, Zhang [9] argues that attention to more contextualized policy tools, including those affecting regulation and spatial planning in cities, can help to minimize their impact.

The United Nations' New Urban Agenda commits member states to achieve sustainable cities [5]. This has triggered a growing call from sanitation experts from development banks, government agencies, non-governmental organizations (NGOs), research institutions and the private sector for increased citywide, inclusive sanitation investments that respond to the needs of all urban dwellers [3]. Principles of the recently emerging citywide inclusive sanitation (CWIS) approach address areas of integrated urban development planning and implementation to achieve coordinated provision of sanitation alongside other basic services. These other services include water supply, stormwater drainage and solid waste management, as well as paving and affordable housing [3]. Former large-scale urban upgrading in India adopted such integrated approaches (see Section 2.1.2), recognizing that broader impacts, such as improved wellbeing and quality of life outcomes, could be achieved for the urban poor [10]. It is therefore timely to reconsider approaches to integrated urban service provision, of which sanitation is an essential and yet often neglected component [11].

\subsubsection{Approaches to Urban Sanitation Development}

Reflecting on the range of reviewed literature, three distinctly different formulations of urban development policy and planning were identified. Within these, sanitation interventions have developed through varied means, namely: Independently from other services (as with Senegal's sanitation improvement programme in Dakar, PAQPUD [12] (p.362)); as part of urban development planning through integrated urban service provision (as with India's Slum Improvement Project [13] (p.102)); or as part of an incremental approach (as with Indonesia's Sanitation Sector Development Program [14] (p.19)). These case locations have been purposefully selected as well documented examples illustrating different approaches to urban sanitation development.

Stand-alone sanitation interventions: Addressing a backlog of sanitation needs in Dakar Senegal. Many urban plans and institutional frameworks operate in non-integrated ways and deliver stand-alone sanitation service interventions. This may be intentional, to address previous neglect or a lack of government prioritization towards sanitation improvements [11,15]. In the case of Dakar, Senegal a stand-alone sanitation intervention sought significant improvements in service outputs and broader development objectives. Senegal's PAQPUD ('programme d'amélioration de l'assainissement des quartiers périurbains de Dakar', or 'sanitation improvement programme for peri-urban districts of Dakar') was a national sanitation strategy offering sanitation and greywater management options. From 2002-2008, 11 lower-income districts of the Dakar metropolitan area benefitted from improved sanitation, ranging from greywater management and onsite latrines, to community-level settled sewerage networks [12]. PAQPUD's achievements were aided by prioritizing appropriate stand-alone sanitation interventions, but it failed to address associated infrastructure and services to achieve wider development impacts. Under the PAQPUD, households could choose from a catalogue of technology options. The high uptake of sink and soakaway facilities for household and community use provided an affordable solution to neighbourhood disputes over poor greywater management [16], but uptake of the (more expensive) latrine option was lower than anticipated. Ten small low-cost sewerage systems, constructed with leveraged public finance and household investments [12], subsequently failed under poor operation and management. The scheme also failed to address the damage to infrastructure (including to water supply and sanitation networks) caused by recurrent and intensifying flooding in the region.

Incremental approaches: Responding to a constrained resource environment in Indonesia. Integrated approaches may be considered too complex to deliver successful outcomes, particularly in resource-constrained environments with limited capacity and high levels of uncertainty. In such situations incremental approaches to sanitation investments have been found to be "appropriate, affordable, locally owned and in many cases progressive" [17] (p.3). Abbott [18] identifies a strength of 
incremental processes, whereby the level of infrastructure development matches what the community and/or local government has the capacity to manage. It can offer greater flexibility than holistic planning approaches, but the danger remains that incremental processes can adopt a mechanistic approach. When driven by sector-focused infrastructure priorities, incremental change may fail to address area-wide upgrading within the broader scope of social and economic development [18]. It can also face barriers from external financing when this is constrained to defined outputs and short timescales. These often run contrary to the need for locally-owned, flexible and progressive investments [17].

Indonesia's Sanitation Sector Development Program (SSDP, 2006-2010) invested significant resources to strengthen the enabling environment for sanitation as part of an incremental approach to urban development. The program was intent on establishing a framework for poor-inclusive sanitation services through "effective and coordinated policy-making, institutional reform, strategic planning and awareness building" [14] (p.6). Central and local government investments were substantially increased for sanitation, enabling the preparation of national and city-level policy and institutional frameworks. Twelve city-level sanitation strategies were also prepared before any significant infrastructure investment occurred [14]. While the program was identified as a success in itself, subsequent planning and implementation processes were often formulaic. This resulted from inadequate local capacity and commitment to quality, and insufficient accountability mechanisms to ensure investments were directed to sustainable sanitation outcomes $[19,20]$.

Integrated approaches: Potential for broader outcomes in India. Much of the slum improvement work in low-income countries in the 1970s-1990s was inspired by John F. Turner's self-help model [21] in which the state focused on provision of basic services, while enabling families to build and incrementally improve housing for themselves [22].

A notable example of this integrated approach to urban improvement is the Government of India's Slum Improvement Project (SIP) implemented across cities in India in the 1980s and 1990s. These SIPs incorporated water, sanitation, solid waste, drainage and road improvements to improve the quality of the city environment. They were seen as contributing towards addressing residents' perceptions of 'quality of life', as key to the alleviation of poverty $[10,13]$. Significant improvements in basic services in the city slums resulted. Notable broader benefits included income generation, enhanced status for women and household investments in upgraded dwellings. Calcutta's Metropolitan Development Authority engaged communities with councillors and contractors in the formulation, testing and monitoring of infrastructure provision and quality. Together with community-led maintenance, this helped to prolong the life of assets [23,24]. Further impact assessments highlighted improved infrastructure as enabling economic and social activity, primarily through increased physical access and extended use of public spaces after dark. Such impacts were perceived by residents as significant 'quality of life' factors [18].

\subsubsection{Addressing Complexities: The Enabling Environment}

The importance of an 'enabling environment' to achieve effective sanitation outcomes is now well recognized. Its analysis is increasingly prominent within service assessments and planning [2,25]. Scott et al.'s Sanitation Cityscape overlays domains (living environment, service delivery environment and the enabling environment) onto a linear service delivery model to better target interventions [26]. Recent integration of governance and political economy analysis, as an explicit part of the enabling environment, is improving understanding of why services operate as they do [27,28]. Participatory governance mechanisms may be considered a prerequisite for holding service providers to account against service standards. In practice however, it has been found to have little impact on user satisfaction levels, particularly in informal settlements [29]. Such developments in understanding are addressing the growing complexity of service provision in rapidly expanding cities. Here, service improvement planning, land use planning and tenure insecurity operate within a constantly changing environment of migration, growing inequalities, uncertain budgets for basic services and climate change [15]. 


\subsubsection{The Position Statement}

In reviewing the literature, categorizing the different approaches to developing urban sanitation in published case examples of each approach, the authors developed the following position statement: More sustainable and effective sanitation outcomes, and wider development impacts, will be achieved if sanitation is integrated with other basic urban services. From this, a set of supporting arguments and counterarguments were identified as to why integrating urban sanitation with other basic services is necessary to achieve greater development outcomes.

Further, three broad foundational components of an enabling environment for effective service integration emerged (as highlighted in the case examples from Senegal, Indonesia and India). These were: Local ownership, leadership and capacity; the policy, legal and regulatory environment; and institutional arrangements. Alongside these "how" components, the authors identified actions required for each component to be realized. These elements are central to defining the policy shift that is implied by the adoption of a more integrated approach to basic urban services.

The position statement, supporting arguments, counterarguments, the how components and identified actions formed the starting point of the next phase of study.

\subsection{The Delphi Expert Consensus Survey Method}

The authors then sought to solicit wider expert opinion to support, or challenge, the initial position statement and arguments. Further, the authors wanted to explore if there was expert consensus on how to achieve better integration of sanitation into other basic urban services in practice. A Delphi expert consensus survey collects a range of opinions from selected experts, allowing consensus to develop through iterative rounds of data gathering and analysis [30,31]. The Delphi method was therefore selected as a reliable and structured method to achieve this desired outcome. A Delphi survey of three-rounds was selected. Round 1 was designed to enable experts to provide additional qualitative data (in the form of expressed opinions) around the position statement [32], before moving to subsequent rounds for scoring of the statements (Round 2) and ranking them in terms of priority statements (Round 3) to identify levels of consensus and prioritisation.

\subsection{Delphi Participants}

In planning the Delphi survey, 50 potential participants were identified by the authors. Each was known to at least one of the authors to have extensive experience and working knowledge in the core disciplinary categories of urban sanitation or urban development. Experts were then scored by the authors for relevance and potential contribution within these categories. Scoring criteria was based on representation from both the global north and global south, plus work experience across local and national governments, international NGOs and development partners, leading academic and private sector stakeholders. Collated results identified the group of 27 experts to invite to participate in the Delphi survey (Table 1).

Table 1. Categorization of experts selected for the Delphi survey.

\begin{tabular}{cccccc}
\hline \multirow{2}{*}{ Main Employment: } & \multicolumn{2}{c}{ Expertise in Urban Sanitation } & \multicolumn{2}{c}{ Expertise in Urban Development } & Total \\
\cline { 2 - 6 } & Global North & Global South & Global North & Global South & \\
\hline Government & 0 & 2 & 0 & 3 & $\mathbf{5}$ \\
\hline NGO & 3 & 0 & 1 & 1 & $\mathbf{5}$ \\
\hline Development partner & 3 & 2 & 2 & 0 & $\mathbf{7}$ \\
\hline Academia & 3 & 0 & 2 & 0 & $\mathbf{5}$ \\
\hline Private sector & 2 & 1 & 1 & 1 & $\mathbf{5}$ \\
\hline Total & $\mathbf{1 1}$ & $\mathbf{5}$ & $\mathbf{6}$ & $\mathbf{5}$ & $\mathbf{2 7}$ \\
\hline
\end{tabular}


By following a rigorous Delphi method with attention to its core principles, good response rates were achieved. Of the initial 27 participants, the 13 participants who completed all three rounds represented all core disciplines and stakeholder groups, with a sample of sufficient size to achieve valid findings [33,34]. Each survey round was piloted and amended before being administered online. Ethical approval was granted by Loughborough University's Ethics Approvals (Human Participants) Sub-Committee (ref. DT_4697, 05/10/2018). Anonymity of participants and their responses was maintained throughout the survey, to prevent any bias or dominance from individuals, disciplines or organizational perspectives in the process.

\subsection{Delphi Survey Design}

Round 1 was designed to enable experts to provide additional qualitative data (in the form of expressed opinions) [8], before moving to subsequent rounds for scoring (Round 2) and ranking (Round 3) statements to identify levels of consensus agreement.

To reflect the extent and complexity of the subject for the Delphi survey, initial arguments for and against integration were broadened out to generalizable statements. This would allow experts' opinions to reflect their personal experience of different approaches across many settings. The survey avoided focusing on context-specific reflections (which were nonetheless captured through additional comments, where given), in order to solicit opinions, priorities and consensus addressing the broader complexities.

By aggregating a wider set of solicited informed opinions, the process led to identified consensus around the why and how of integrating basic urban services [34]. The process as followed in the survey is summarized in Figure 1.

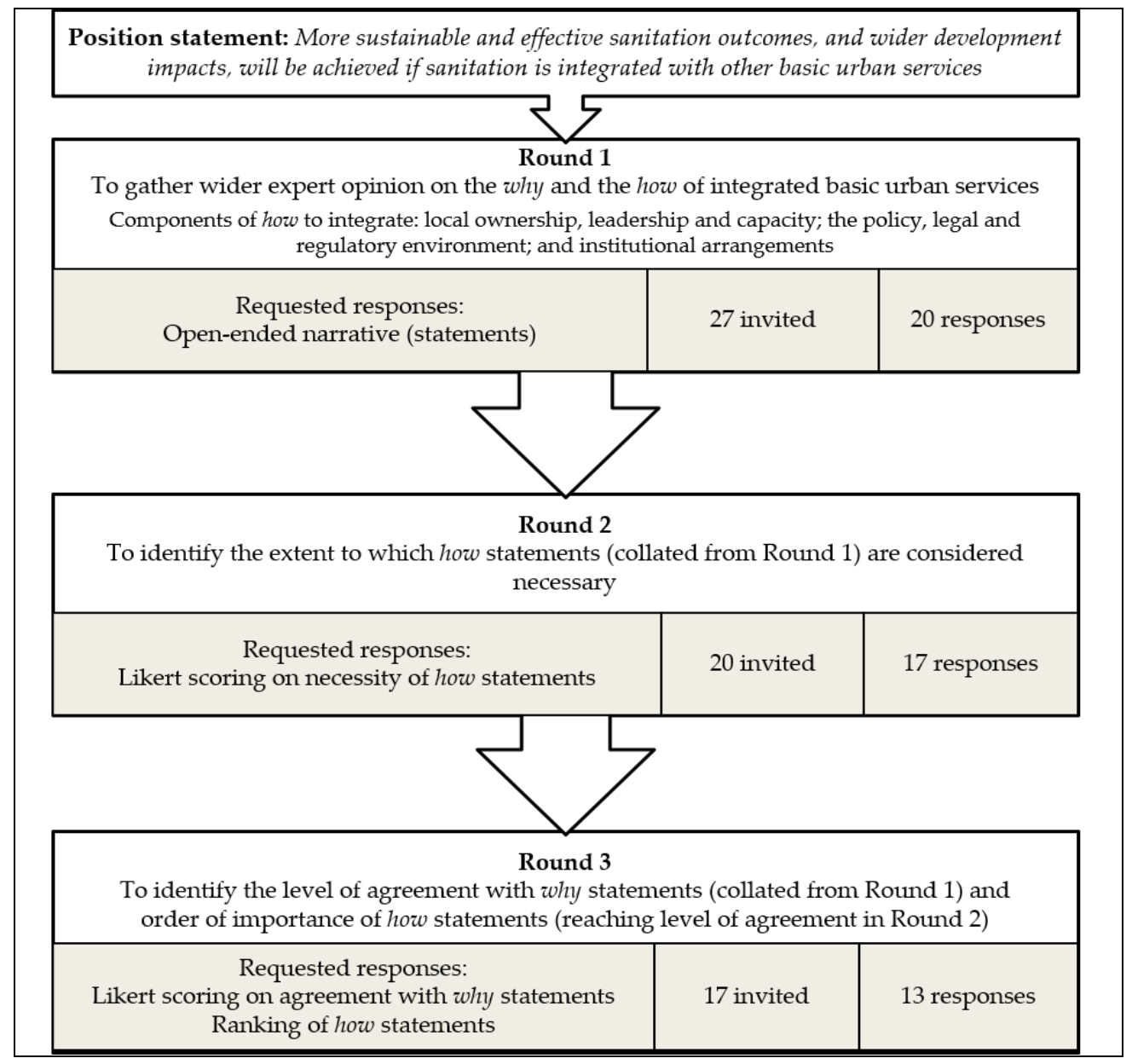

Figure 1. The three-round Delphi survey process. 
Specifically, the three rounds of the Delphi survey (administered from December 2018 to July 2019) comprised the following actions:

Round 1: The first round was to gather wide expert opinion on the "why" and the "how" of integrated basic urban services. The first 'open-ended' round presented to the participants nine arguments and counterarguments to the position statement ("the why"). Participants were also presented with three "how" components. These were enabling elements of integrated services, each with a purpose and activities or actions (15 in total) that would be required to support their achievement. Participants were invited to add further arguments, counterarguments and "how" components (or contributing activities or actions) where they perceived gaps, or to represent their views differently [35]. This first qualitative round was to extend and guide the statements to be used for the further rounds [32]. Qualitative analysis on the results of Round 1 was used to identify themes and develop consolidated statements to take forward to Rounds 2 and 3.

Round 2: This Round focused on the "how" components and which are considered necessary. Consolidated "how" statements from Round 1 were randomized within their relevant enabling component. Participants were then asked to rate how necessary they felt each element to be to achieve the respective component using a four-point Likert scale: Essential, important, of some value or unimportant.

Round 3: This consisted of two parts. Respondents were first presented with the eight "why" arguments supportive of integration, and four challenges to integration, developed from responses to Round 1. Respondents rated their level of agreement with each statement, based on a five-point Likert scale: Strongly agree, agree, neither agree nor disagree, disagree or strongly disagree. The percentage of consensus agreement (as in Round 2) and ranking (based on the mean value of all responses, which were allocated scores 1-5) was calculated for each statement. Secondly, respondents were presented with the agreed "how" statements from Round 2. The list of elements was randomized within each enabling component. Respondents ranked each "how" statement in order of how important they perceived it was to help achieve the respective enabling component.

\section{Results}

Results of the Delphi survey are presented here in relation to the two major components framing the survey: Why integrating urban sanitation with other basic urban services is considered necessary to achieve wider development outcomes, and how this can be achieved through actions aligned to three enabling components. The results that follow, together with implications of results achieving highest consensus agreement and additional quotations (refer to the Discussion that follows in Section 4), are from experts completing the final survey round. These are considered to be the most significant outcomes of the survey process.

\subsection{Response Rates}

Round 1: 147 unique statements were provided by 20 respondents ( $74 \%$ response rate). Qualitative analysis was employed on the results of Round 1 to identify themes within the responses, collate statements within those themes and develop 12 consolidated "why" statements and 48 "how" statements to take forward to Rounds 2 and 3 (Table 1).

Round 2: 17 completed surveys were received from the 20 respondents completing Round 1 (85\% response rate). A level of agreement ranging from $70 \%$ to over $80 \%$ can be taken to indicate a strong level of consensus [32]. Consensus was considered to be achieved if $>14$ of the 17 experts responding $(>82 \%)$ rated the element as either "essential" or "important". Analysis of the results identified consensus on 28 "how" elements to take forward into Round 3.

Round 3: 13 responses were received for Round 3 (76\% response rate). Rank average scores were calculated for all scores from all responses to account for respondents who gave equal rankings to more than one element in a group. The rank average scores per respondent were used to identify the consolidated rankings across all respondents. 


\subsection{Position Statement, Arguments and Counterarguments to Integration: The Why}

Table 2 shows the 12 "why" statements (supporting arguments and counterarguments) formulated from the responses to Round 1, as ranked from the results of Round 3. It also shows the percentage level of consensus agreement for these statements, calculated from the results.

Table 2. The Why statements as ranked from Round 3, showing percentage agreement among experts.

\begin{tabular}{|c|c|c|}
\hline Rank & Supporting arguments (as ranked from Round 3) & Agreement \\
\hline 1st & $\begin{array}{l}\text { Integration addresses the reality that a range of basic services (water supply, } \\
\text { sanitation, solid waste management, roads and drainage) are inextricably } \\
\text { interdependent in urban settings. Integration enhances planning and } \\
\text { improvement across all services, recognising that neglect of one service } \\
\text { compromises the benefits to be gained from improving the other services. }\end{array}$ & $100 \%$ \\
\hline 2nd & $\begin{array}{l}\text { Combining sanitation with water supply in utilities, can provide an institutional } \\
\text { home and the stable revenues necessary to achieve improved sanitation services. } \\
\text { It does not require full integration across all basic services. However, whether } \\
\text { service delivery is integrated or not, each sub-sector should have a } \\
\text { comprehensive understanding of the broader urban context and how each } \\
\text { service works as part of the whole. }\end{array}$ & $92 \%$ \\
\hline 3 rd & $\begin{array}{l}\text { Integration offers the scope to maximise synergies with factors influencing the } \\
\text { enabling environment. These can range in scope from migration, spatial } \\
\text { planning, land and tenure arrangements, to civil action, or microfinance options. } \\
\text { Where such issues are addressed discretely, barriers to improved services are } \\
\text { more likely to result. }\end{array}$ & $85 \%$ \\
\hline 4th & $\begin{array}{l}\text { Bundling sanitation with other urban development initiatives can address the } \\
\text { de-prioritisation (by citizens and politicians alike) of an 'invisible' basic service } \\
\text { over very visible improvements to, for example, roads, drainage or solid } \\
\text { waste.Integration strengthens the "value proposition" of safely managed } \\
\text { sanitation, when delivered as part of wider environmental and health } \\
\text { improvements.Working collaboratively across sectors helps to optimise resources } \\
\text { for urban authorities, with the potential to leverage complimentary financing. It } \\
\text { can overcome funds being prioritized for improvements to more visible services } \\
\text { (including water, drainage, solid waste), which is common in situations of } \\
\text { uncertain budgets. }\end{array}$ & $77 \%$ \\
\hline
\end{tabular}

Adopting integrated planning approaches can offer a way to strengthen collaboration across several departments or ministries, enabling a more rational

7th allocation of roles and responsibilities, human resources, finance, equipment and tools. It can also respond to the gaps that may remain between these agencies and autonomous utilities.

Integration across services can overcome bureaucratic barriers to enhanced

8th service provision that discriminate against the unfulfilled rights of excluded residents when services are addressed separately.

\begin{tabular}{clc}
\hline Rank & Counterarguments (as ranked from Round 3) & Agreement \\
\hline 1st & $\begin{array}{l}\text { Attempts to implement integrated programmes can be severely delayed or } \\
\text { abandoned because the individual departmental imperatives or funding cycles } \\
\text { are not aligned. }\end{array}$ & $77 \%$ \\
\hline 2nd & $\begin{array}{l}\text { A lack of prior integrated interventions often leaves sanitation neglected, } \\
\text { overlooked and underfunded. Specific sanitation needs and demands, typically } \\
\text { of marginalised groups, may warrant a sanitation-only intervention. }\end{array}$ & $69 \%$ \\
\hline 3rd & $\begin{array}{l}\text { Integration requires more time, skills and human resources than may be available } \\
\text { in Municipal level institutions, preventing the planning and development of } \\
\text { associated services in a logical manner to deliver safe services. }\end{array}$ & $62 \%$ \\
\hline 4th & $\begin{array}{l}\text { In the absence of capacity to coordinate, it may prove more effective for services } \\
\text { to be organized in discrete sector-based departments, each with clear mandates } \\
\text { and work processes, requisite skills and resources, while working collaboratively } \\
\text { towards an overarching goal. }\end{array}$ & $54 \%$ \\
\hline
\end{tabular}




\subsection{Enabling Components of Integration: The How}

Table 3 shows the 28 elements achieving consensus ( $>82 \%)$ in Round 2 that were taken forward to Round 3. It shows these elements as ranked from the results of Round 3, within each component. It also shows the level of consensus agreement calculated from the results of Round 2, for each element.

Table 3. Enabling components and the 'agreed' How elements as ranked from Round 3, with percentage agreement from Round 2.

\section{Component 1: Local ownership, leadership and capacity}

Sustainable improvement only happens where there is local ownership and leadership, and local capacity to plan and manage it.

\begin{tabular}{|c|c|c|}
\hline Rank & $\begin{array}{l}\text { Elements required to achieve the enabling component } \\
\text { (as ranked from Round 3) }\end{array}$ & $\begin{array}{c}\text { Agreement } \\
\text { (from Round 2) }\end{array}$ \\
\hline 1 st & $\begin{array}{l}\text { Strong local government leadership and commitment and an agent of change with } \\
\text { a clear vision. This might be an individual or organisation with sufficient influence, } \\
\text { not necessarily in a designated role but rather someone who is best placed to 'get } \\
\text { things done' }\end{array}$ & $100 \%$ \\
\hline $2 \mathrm{nd}$ & $\begin{array}{l}\text { Accountability of local government: Clearly defined roles and targets } \\
\text { for implementation }\end{array}$ & $88 \%$ \\
\hline $3 r d$ & $\begin{array}{l}\text { Available budgets for local government to enable integrated strategic urban } \\
\text { development planning to take place }\end{array}$ & $88 \%$ \\
\hline 4 th & $\begin{array}{l}\text { The professionalisation of a service and a mandated local agency with adequate } \\
\text { capacity to lead or coordinate interventions on which sustainable sanitation } \\
\text { services can be provided. (This could be, for example, one agency for water and } \\
\text { sanitation, as water supply service provision can provide a robust platform with } \\
\text { economies of scope and scale). }\end{array}$ & $88 \%$ \\
\hline 5 th & $\begin{array}{l}\text { Aligned incentives and mechanisms for leveraging financial revenue from national } \\
\text { (e.g., fiscal transfers) and local (e.g., municipal budgets) government sources. }\end{array}$ & $88 \%$ \\
\hline 6th & Administrative capacity to implement. & $88 \%$ \\
\hline 7th & $\begin{array}{c}\text { A clear policy of achieving equitable and inclusive services for all urban residents, } \\
\text { where excluded / marginalised groups are actively involved in decisions regarding } \\
\text { fulfilling their rights to urban services, including sanitation design and } \\
\text { implementation. }\end{array}$ & $94 \%$ \\
\hline 8th & $\begin{array}{l}\text { An initial 'spark' (i.e. a stimulus for change), with early funding and a champion to } \\
\text { drive change, likely focusing on a specific gap or need, which can lead to } \\
\text { visible change. }\end{array}$ & $88 \%$ \\
\hline 9th & $\begin{array}{c}\text { National governments providing technical assistance to build capacity of local } \\
\text { institutions, as well as human resources. }\end{array}$ & $88 \%$ \\
\hline 10th & $\begin{array}{l}\text { Sanitation as part of a broader agenda to elevate and fulfil residents' rights, } \\
\text { especially excluded and disadvantaged residents. This means considering } \\
\text { sanitation in the continuum of urban services that are unfulfilled. }\end{array}$ & $88 \%$ \\
\hline \multicolumn{3}{|c|}{$\begin{array}{l}\text { Component 2. The policy, legal and regulatory environment } \\
\text { City-wide integrated sanitation can only occur within a policy, legal and regulatory environment that } \\
\text { focuses on services and outcomes in addition to infrastructure and inputs. }\end{array}$} \\
\hline Rank & $\begin{array}{l}\text { Elements required to achieve the enabling component } \\
\text { (as ranked from Round 3) }\end{array}$ & $\begin{array}{c}\text { Agreement } \\
\text { (from Round 2) }\end{array}$ \\
\hline 1 st & A clear and shared political vision with a strategy to achieve it. & $100 \%$ \\
\hline 2nd & $\begin{array}{l}\text { Political and regulatory recognition and planning culture that enable the provision } \\
\text { of infrastructure and service components to achieve integrated basic service } \\
\text { delivery to all parts of the city. }\end{array}$ & $88 \%$ \\
\hline $3 \mathrm{rd}$ & $\begin{array}{l}\text { Incremental approaches across all basic services that build on what already exists } \\
\text { and allow sequencing of interventions within a wider urban development strategy. }\end{array}$ & $100 \%$ \\
\hline
\end{tabular}


Table 3. Cont.

\begin{tabular}{|c|c|c|}
\hline 4 th & $\begin{array}{l}\text { A broad range of appropriate sanitation options, with the required mechanisms of } \\
\text { service delivery and financing, designed to ensure at least basic services reach all } \\
\text { parts of the city. }\end{array}$ & $100 \%$ \\
\hline 5 th & Robust governance accountability mechanisms and remedies. & $100 \%$ \\
\hline 6th & Delineation of roles and responsibilities in governance and service provision. & $100 \%$ \\
\hline 7th & $\begin{array}{l}\text { Explicit mention and local mechanisms for inclusion of marginalised citizens, } \\
\text { community-driven initiatives and informal settlements. This includes consultation, } \\
\text { decision-making, financial mechanisms and selecting appropriate solutions. }\end{array}$ & $100 \%$ \\
\hline 8th & $\begin{array}{l}\text { A learning agenda and responsive environment: Data and evidence of what works } \\
\text { and what doesn't work, appropriate innovation, understanding the negative } \\
\text { impacts of poor urban services on health, environment and viability of the } \\
\text { urban area. }\end{array}$ & $94 \%$ \\
\hline 9th & $\begin{array}{c}\text { National regulation and policies providing the appropriate legal framework, } \\
\text { with clearly defined standards. }\end{array}$ & $94 \%$ \\
\hline 10th & $\begin{array}{l}\text { Norms and regulatory standards safeguarding urban residents (for example: } \\
\text { Minimum requirements for services in informal settlements, water quality } \\
\text { monitoring, housing and rental norms and standards). }\end{array}$ & $100 \%$ \\
\hline \multicolumn{3}{|c|}{$\begin{array}{l}\text { Component } 3 \text {. Institutional arrangements } \\
\text { Development finance institutions and government departments, which have a strong tendency to work in silos } \\
\text { need to be better configured to deliver the multi-sectoral support that an integrated, incremental, locally-based } \\
\text { approach requires. }\end{array}$} \\
\hline Rank & $\begin{array}{l}\text { Elements required to achieve the enabling component } \\
\text { (as ranked from Round 3) }\end{array}$ & $\begin{array}{c}\text { Agreement } \\
\text { (from Round 2) }\end{array}$ \\
\hline 1 st & $\begin{array}{c}\text { Strong leadership that can overcome political pressures working against } \\
\text { integrated services. }\end{array}$ & $94 \%$ \\
\hline 2nd & $\begin{array}{l}\text { Adequate budgets and financing mechanisms to plan, develop and maintain } \\
\text { services in an integrated manner. }\end{array}$ & $100 \%$ \\
\hline $3 \mathrm{rd}$ & $\begin{array}{l}\text { Capable personnel in adequate number attracted to work in the sector } \\
\text { (e.g., through the use of performance-based incentives). }\end{array}$ & $94 \%$ \\
\hline 4 th & $\begin{array}{l}\text { Budget and finance mechanisms which allow for co-financing-recognising that } \\
\text { public finance will probably be required for elements of basic services, including } \\
\text { social elements, in low income communities. }\end{array}$ & $94 \%$ \\
\hline 5 th & $\begin{array}{l}\text { Training and capacity development of personnel serving the sector to achieve } \\
\text { effective problem solving in complex urban environments. }\end{array}$ & $94 \%$ \\
\hline 6th & $\begin{array}{c}\text { Clear systems of governance to ensure transparency and mutual accountability } \\
\text { through all levels of engagement (e.g., donors and government, service providers } \\
\text { and citizens) in the effective use of resources and delivery of services to } \\
\text { achieve goals. }\end{array}$ & $88 \%$ \\
\hline 7th & $\begin{array}{l}\text { Adequate timeframes and flexibility within international finance, development and } \\
\text { government programmes to develop local ownership and capacity to achieve } \\
\text { desired change. }\end{array}$ & $94 \%$ \\
\hline 8th & $\begin{array}{c}\text { Capacity for the design, implementation and regulation of } \\
\text { non-conventional solutions. }\end{array}$ & $100 \%$ \\
\hline
\end{tabular}

\section{Discussion}

The statements achieving highest consensus agreement in relation to why and how to deliver integrated basic urban services are discussed here. Where certain priorities were distinct to experts representing the global north or global south, these are also noted. Actions around integration deemed common to other development sectors are considered, as providing opportunities for enhanced cross-sectoral learning and dialogue. 


\subsection{Primary Reasons and Means for Integrated Services}

Statements and elements achieving the highest rankings in Round 3 (shown in Table 4) represent the combined expert panel's primary arguments for and against integrating sanitation into basic urban service development and the priority actions necessary to achieve it.

Table 4. Highest ranked "why" statements and "how" elements.

Why integrate sanitation with other basic urban services

\section{Supporting arguments}

1. Integration addresses the reality that a range of basic services (water supply, sanitation, solid waste management, roads and drainage) are inextricably interdependent in urban settings. Integration enhances planning and improvement across all services, recognising that neglect of one service compromises the benefits to be gained from improving the other services.

2. Combining sanitation with water supply in utilities, can provide an institutional home and the stable revenues necessary to achieve improved sanitation services. It does not require full integration across all basic services. However, whether service delivery is integrated or not, each sub-sector should have a comprehensive understanding of the broader urban context and how each service works as part of the whole.

3. Integration offers the scope to maximise synergies with factors influencing the enabling environment. These can range in scope from migration, spatial planning, land and tenure arrangements, to civil action, or microfinance options. Where such issues are addressed discretely, barriers to improved services are more likely to result.

\section{Counterarguments}

1. Attempts to implement integrated programmes can be severely delayed or abandoned because the individual departmental imperatives or funding cycles are not aligned.

2. A lack of prior integrated interventions often leaves sanitation neglected, overlooked and underfunded. Specific sanitation needs and demands, typically of marginalised groups, may warrant a sanitation-only intervention.

3. Integration requires more time, skills and human resources than may be available in Municipal level institutions, preventing the planning and development of associated services in a logical manner to deliver safe services.

How to integrate sanitation with other basic urban services

\section{Local ownership, leadership and capacity}

1. Strong local government leadership and commitment and an agent of change with a clear vision. This might be an individual or organisation with sufficient influence, not necessarily in a designated role but rather someone who is best placed to 'get things done'.

2. Accountability of local government: Clearly defined roles and targets for implementation.

3. Available budgets for local government to enable integrated strategic urban development planning to take place.

\section{Policy and legal frameworks}

1. A clear and shared political vision with a strategy to achieve it.

2. Political and regulatory recognition and planning culture that enable the provision of infrastructure and service components to achieve integrated basic service delivery to all parts of the city.

3. Incremental approaches across all basic services that build on what already exists and allow sequencing of interventions within a wider urban development strategy.

\section{Institutional arrangements}

1. Strong leadership that can overcome political pressures working against integrated services.

2. Adequate budgets and financing mechanisms to plan, develop and maintain services in an integrated manner.

3. Capable personnel in adequate number attracted to work in the sector (e.g., through the use of performance-based incentives).

Regarding the reason why to integrate sanitation with other basic urban services, all the expert panel's primary supportive arguments reflect the interdependency of services within urban contexts. These are not merely abstract concepts, or a reflection of institutional mandates, but rather they 
articulate the inextricable physical interlinkages between services and the resulting outcomes of neglect for any one of them. For example: Increased household water supply affects the volumes of greywater or faecal sludge produced that then require safe management. Failure to consider greywater and faecal sludge management can, at least in part, counter the health benefits of improved water supply. Justification for integration on technical grounds was seen as a "strong enough driver" (Expert \#1) in and of itself. Beyond the technical aspects, there was consensus that co-locating sanitation services in utilities responsible for water services provides a mechanism and stability to exploit synergies of integration (whether in full or partially). This can then leverage improvements in the enabling environment across other basic services. Notably for sanitation, this means the utility mandate is not limited to specific sanitation technologies (e.g., sewers) but extends to delivering sanitation service outcomes through both sewered and non-sewered technologies. Experts representing the global south (4 of the respondents to Round 3) also strongly supported the view that working collaboratively can optimize available resources and leverage complimentary finance for sanitation. They also felt that sanitation achieves enhanced status when integral to wider environmental and health improvements.

The expert panel all recognized that misaligned funding cycles, political imperatives, historical neglect of sanitation and constrained resource capacity at local levels of administration are compelling counterarguments against integration. Notably, specific sanitation needs and demands, typically of marginalized groups, may also warrant a sanitation-only intervention. These barriers and challenges must be considered and overcome in working towards an appropriate way forward.

When considering how to achieve integration of basic services, all experts prioritized strong leadership, robust governance and accountability mechanisms, underpinned by clarity of roles and targets for implementation. The essential value of empowered change-agents, who can align actors around a shared political vision and urban development strategy, was equally recognized. Experts representing the global north (nine of the respondents to Round 3) also emphasized actions to delineate roles and responsibilities between governance and service provision, to ensure available budgets for local integrated planning and adequate financing mechanisms for the continuation of integrated services. Those representing the global south (four respondents) emphasized the actions that could enable better local government accountability. We suggest that accountable roles and targets need to become explicit in strategic implementation plans, against which appropriate financial and human resources can be allocated.

\subsection{How Feasible is Integration in Practice?}

Many of the expert panel also provided insights on the contextual challenges they see as influencing the scope of integration, through their additional comments. Analysis of these insights reflect how realistic or appropriate integrated approaches are seen to work in practice, based on realities of the developing cities in which they have experience

Integrating services, or focusing on sanitation-only programmes, has varied over time in many contexts, with the suitability and feasibility of integration being "related to the stage (level of maturity) that government services and/or utilities are in" (Expert \#7), and the extent of public confidence to "engage in the partnership activities needed to deliver [it]" (Expert \#1). The strength of political will to achieve integration, coupled with clearly enforced legislation, was considered critical in some contexts (Expert \#9). Those working within government institutions were also seen to need reassurances that engaging in integrated processes will not have negative consequences "if things take more time or have less tangible outcomes" (Expert \#1). The political economy realities of "winners and losers from integration" in any given context may help explain the fundamental challenges behind starting and sustaining integration (Expert \#2).

The current nature of funding cycles and inherent difficulties in demonstrating a strong business case for sanitation were seen to make integration "nearly impossible" in practice, particularly as integrated funding could become a "recipe for failure due to the potentially resulting lack of clarity in institutional roles" (Expert \#4). Opportunities for integrated planning, however, were considered 
as "more feasible" (Expert \#4). The influence of tariffs and an economic regulator were seen as being "important in the actual running of services" phase (Expert \#3), while less significant during the phases of planning and implementing integrated services.

While components of accountability, transparency and the human rights agenda are recognized as integral to urban development, there are many examples of where these components were not practiced and yet countries "still realised sustained sanitation improvements" (Expert \#7), as well as vice versa. The risk of neglect for poor urban communities is likely to remain "whether there is integration or not" (Expert \#1). It cannot be said, however, that sanitation-only interventions will necessarily improve outcomes for such populations. Without concurrent development of, for example, adequate solid waste management services and drainage infrastructure "they will not gain any benefits from a sanitation service" (Expert \#1). Integrating services was considered particularly needed "with regards to spatial planning and construction" (Expert \#9). "Bundling" services may mean, however, that integrating sanitation with drainage infrastructure, for example, is actually "more relevant than bundling sanitation with road construction" (Expert \#3). The growing influence of climate change and increasing cases of water scarcity also mean that "fuller integration of the water cycle in urban areas is going to be become a necessity" (Expert \#12).

Integration requires stakeholders working towards collectively agreed outcomes beyond individual sub-sectoral output targets. The WASH (water, sanitation and hygiene) sector is placing greater emphasis on service delivery outcomes as a means by which wider development outcomes can be attained. As a result, the WASH sector narrative is evolving and maturing within itself, and as a means to better engage with inter-dependent sectors, such as those responsible for urban planning, housing or the environment. Caution was raised by experts around discrete departments working collaboratively towards an overarching goal "when there is no coordination capacity" (Expert \#4). To adopt integrated approaches requires someone at a high level, such as the mayor's office, secretariat of finance or secretariat of planning, who is "empowered for overall implementation" (Expert \#13). While challenges and problems associated with integration were recognized by all experts, it was also noted to be "worth the risks". (Expert \#6).

From such results, we are reminded of the potential benefits of incremental approaches, where integrated approaches are considered too complex to deliver successful outcomes [17] (p.3). Incremental progression across all basic services was recognized among the priorities resulting from the Delphi method. Incremental development requires a capacity to be responsive to what currently exists, allowing sequencing of interventions as and when sufficient resources can deliver them. Within a framework of iterative progress, the development of agreed service level standards, performance targets and service-provider/customer accountability relations would enable dialogue and learning in relation to this priority also. However, while consensus around service level standards across the full range of sanitation service options does not exist, the dialogue will remain challenging.

\subsection{Commonality with Other Development Sectors}

The Delphi process has identified a prioritized set of action areas for how to integrate sanitation with other basic urban services, namely: Leadership, governance, improving accountability against service level indicators, effective planning, finances and sufficient capacity. The process of consensus building provided by the Delphi survey method lends a greater level of granularity around each of these statements (see Table 4). Moreover, these statements are far from unique across many development sectors. As such, they offer potential inroads to strengthen dialogue around aligning and integrating sanitation more closely with other basic urban services.

The agreed areas and actions also suggest opportunities to apply lessons learnt from parallel urban development initiatives to those for sanitation services (by which we mean both sewered and non-sewered sanitation systems). As concurred in recent literature, improved sanitation services can be strengthened through political processes that address the governance constraints commonly experienced across basic services [27]. The process would be further supported by developing and 
establishing clearer planning, procurement and budgeting mechanisms [8], while identifying and filling the human capacity gaps in service delivery, from national to local outreach levels [17]. Accountability, alongside enhanced monitoring, was a significant component of past integrated urban upgrading programmes $[26,29]$. While more recently applied to integrated urban water resources and wastewater management [4], accountability to service levels has received less attention for sanitation service improvements, given the absence of agreed service level standards and indicators.

\subsection{Study Limitations}

The survey raised a few concerns with ranking. Experts noted that "answers would vary a lot depending on local context" (Expert \#5), while a lack of context made ranking statements "quite difficult" (Expert \#10), particularly as "most are very important" (Expert \#3). Experts found the survey "tough" (Expert \#4), particularly where "how" elements applied to more than one component. This was, however, seen as "highlighting the interrelationships" (Expert \#4) between challenges, opportunities and solutions. Further surveys using more precise statements could better capture contextual realities, while being careful not to over-simplify the recognized complexities for the sake of an easier process. A three-round Delphi method requires significant time to enable as many experts to complete each round as possible, while also ensuring rigorous analysis of significant qualitative and quantitative results to represent all contributions. The initially anticipated three month duration extended to seven months, affecting participant engagement.

\section{Conclusions}

The Delphi survey results presented in this paper offer consolidated thinking around two parts of the discourse of integrating urban sanitation. Firstly, the physical interdependencies of sanitation services and other basic urban services emerged as the primary supporting argument as to why sanitation cannot proceed without due consideration of the broader urban planning and spatial development processes. This has not been the modus operandi of recent single-sector approaches where sanitation interventions proceed in isolation to solid waste management, drainage or water supply, and vice versa. The Delphi results confirm consensus that combining sanitation with water supply in utilities can provide both an institutional home and the stable revenues necessary to achieve improved sanitation services. Even so, Delphi respondents also expressed consensus that there may be occasions where specific sanitation needs and demands, typically of marginalised groups, may warrant a sanitation-only intervention. This recognizes that integration requires more time, skills and human resources than may be available in Municipal level institutions, and that achieving integration can delay or even derail programmes, or leave sanitation neglected. Secondly, the Delphi process has validated through consensus a set of priority action areas for how to integrate sanitation with other basic urban services. Those achieving the highest consensus are: Securing political prioritization and leadership for change; addressing urban governance constraints; establishing clearer planning, procurement and budgeting mechanisms; strengthening accountability and enhanced monitoring to agreed service level standards and indicators; and costed and resourced implementation capacity (Table 4). Importantly, these priority action areas relate to improved governance and planning, and stronger national systems, which are not unique to the sanitation sector. We suggest that they are sustained through strong local government leadership and commitment with a clear vision, and provide action areas to target join interventions, benchmark progress and identify synergies with other sectors.

Pragmatically, where does this leave those working to improve sanitation? This paper does not propose full integration across all basic services and revised organizational mandates from sanitation to urban governance. Rather, it suggests each sub-sector gains a comprehensive understanding of the broader urban context and how each service contributes to the whole. If actions are to suit contextual realities that can either drive or constrain integration, this calls for those working in single sector service provision approaches to engage with wider urban service delivery systems and contexts, so that synergies can be maximized where feasible. These contexts may include among others migration, 
spatial planning, land and tenure arrangements, rather than addressing them in isolation. It also calls for sanitation intervention planning to seek alliances and work through incremental approaches that build on what already exists, allowing for sequencing of interventions within a wider urban development strategy.

The SDGs are driving a focus on equitable service outcomes, beyond delivering outputs ('taps and toilets'). The SDG-era sanitation discourse has started to articulate what these service outcomes might mean, particularly with regard to protecting public and environmental health [36]. A contribution of this study to the discourse is that accountability to agreed service level outcomes and indicators, plus the means by which these respond to residents' desired 'quality of life' outcomes, will benefit from reflecting on the notable achievements of past urban upgrading programmes, where these were identified factors of success. When agreed and implemented, these outcomes and their respective indicators will be key to ensuring broader sustainable outcomes in the face of rapid urbanization, spatial and environmental pressures. The process requires an ability to drive integration between those responsible for basic service improvements and those responsible for the broader urban development agenda. Incremental approaches and sequenced interventions can respond to increasing co-ordination capacity, sufficient political leadership and financial commitments, in efforts to achieve better outcomes for all urban residents.

Author Contributions: Conceptualization, R.S., P.S., P.H., I.B. and A.C.; Data curation, R.S., P.S., and A.L.; Formal analysis, R.S., P.S., and A.L.; Methodology, R.S., P.S., P.H., and I.B.; Supervision, R.S.; Validation, R.S. and P.S.; Writing—original draft, R.S., P.S., P.H., and I.B.; Writing—review and editing, R.S., P.S., P.H., I.B., A.C. and A.L.

Funding: This research received no external funding.

Acknowledgments: The authors thank all the experts who gave their time and valuable contributions to the Delphi survey, notably those who completed all three rounds. We would also like to thank those who reviewed the survey questions.

Conflicts of Interest: The authors declare no conflict of interest.

\section{References}

1. Hutchings, P.; Johns, M.; Jornet, D.; Scott, C.; Van den Bossche, Z. A systematic assessment of the pro-poor reach of development bank investments in urban sanitation. J. Water Sanit. Hyg. Dev. 2018, 8, $402-414$. [CrossRef]

2. Scott, P.; Scott, R.E.; Cotton, A.P. Urban sanitation: Where to next? In Local action with international cooperation to improve and sustain water, sanitation and hygiene services. In Proceedings of the 40th WEDC International Conference, Loughborough, UK, 24-28 July 2017; Shaw, R., Ed.; Loughborough University: Loughborough, UK, 2017.

3. Lüthi, C.; Narayan, A.S. Citywide Inclusive Sanitation: Achieving the urban water SDGs. In Perspectives Integrated Policy Briefs: Urban Waters-How Does Water Impact and is Impacted by Cities and Human Settlements? Camarena, L., Machado-Filho, H., Casagrande, L., Byrd, R., Tsakanika, A., Wotton, S., Eds.; World Centre for Sustainable Development: Rio de Janeiro, Brazil, 2018; Volume 1, pp. 11-13. [CrossRef]

4. Rees, J.A. Urban Water and Sanitation Services; an IWRM Approach; Technical Committee (TEC) Background Papers No.11; Global Water Partnership: Stockholm, Sweden, 2006; pp. 1-58.

5. United Nations. New Urban Agenda, United Nations and Habitat III Secretariat. 2017. Available online: http://habitat3.org/wp-content/uploads/NUA-English.pdf (accessed on 1 October 2019).

6. Cities Alliance. Liveable Cities: The Benefits of Urban Environmental Planning; Cities Alliance, United Nations Environment Programme (UNEP), and ICLEI: Washington, DC, USA, 2007; pp. 1-141.

7. Sverdlik, A. Ill-health and poverty: A literature review on health in informal settlements. Environ. Urban. 2011, 23, 123-155. [CrossRef]

8. Amado, M.P.; Ramalhete, I.; Amado, A.R.; Freitas, J.C. Regeneration of informal areas: An integrated approach. Cities 2016, 58, 59-69. [CrossRef]

9. Zhang, X.Q. The trends, promises and challenges of urbanisation in the world. Habitat Int. 2016, 54, 241-252. [CrossRef] 
10. Amis, P. Rethinking UK aid in urban India: Reflections on an impact assessment study of slum improvement projects. Environ. Urban. 2001, 13, 101-113. [CrossRef]

11. Reymond, P.; Renggli, S.; Lüthi, C. Towards Sustainable Sanitation in an Urbanising World. In Sustainable Urbanization; Ergen, M., Ed.; InTech Open: London, UK, 2016; Volume 2, pp. 115-134. [CrossRef]

12. Norman, G.; Scott, P.; Pedley, S. The PAQPUD settled sewerage project (Dakar, Senegal): Problems arising, lessons learned. Habitat Int. 2011, 35, 361-371. [CrossRef]

13. Parikh, P.; Parikh, H.; McRobie, A. The role of infrastructure in improving human settlements. Urban Des. Plan. 2013, 166, 101-118. [CrossRef]

14. WSP. Lessons in Urban Sanitation Development: Indonesia Sanitation Sector Development Programme 2006-2010; Water and Sanitation Program of the World Bank; World Bank: Washington, DC, USA, 2011.

15. Andersson, K.; Dickin, S.; Rosemarin, A. Towards "sustainable" sanitation: Challenges and opportunities in urban areas. Sustainability 2016, 8, 1289. [CrossRef]

16. Trémolet, S.; Kolsky, P.; Perez, E. Financing On-Site Sanitation for the Poor: A Six Country Comparative Review and Analysis; Water and Sanitation Program Working Paper; World Bank: Washington, DC, USA, 2010.

17. Mitlin, D. Building towards a Future in Which Urban Sanitation "Leaves no one behind." Environment Urbanization Briefs. 2015. Available online: https://pubs.iied.org/10765IIED/ (accessed on 1 October 2019).

18. Abbott, J. An analysis of informal settlement upgrading and critique of existing methodological approaches. Habitat Int. 2002, 26, 303-315. [CrossRef]

19. WSP. Political Economy of Sanitation in Indonesia; Water and Sanitation Program of the World Bank; World Bank: Washington, DC, USA, 2014.

20. ISF-UTS \& SNV. Are we doing the Right Thing? Critical Questioning for City Sanitation Planning; Prepared by Institute for Sustainable Futures; University of Technology Sydney and SNV Netherlands Development Organisation: Sydney, Australia, 2016.

21. Turner, J.F.C. Housing as a Verb. In Freedom to Build, Dweller Control of the Housing Process; Turner, J.F.C., Fichter, R., Eds.; Collier Macmillan: New York, NY, USA, 1972; pp. 148-175.

22. Hardoy, J.E.; Satterthwaite, D. Building the future city. In Cities in the Developing World: Issues, Theory, and Policy; Gugler, J., Ed.; Oxford University Press: Oxford, UK, 1997; pp. 265-279.

23. Kar, K. Participatory Impact Assessment: Calcutta Slum Improvement Project; Department for International Development (DFID) Urban Poverty Office: New Delhi, India, 1997.

24. Cotton, A.P.; Sohail, M.; Tayler, W.K. Community Initiatives in Urban Infrastructure; Water Engineering and Development Centre, Loughborough University: Loughborough, UK, 1998; pp. 1-95.

25. Peal, A.; Evans, B.; Blackett, I.; Hawkins, P.; Heymans, C. Fecal sludge management (FSM): Analytical tools for assessing FSM in cities. J. Water Sanit. Hyg. Dev. 2014, 4, 371-383. [CrossRef]

26. Scott, P.; Cotton, A.; Sohail, M. Using tenure to build a "sanitation cityscape": Narrowing decisions for targeted sanitation interventions. Environ. Urban. 2015, 27, 389-406. [CrossRef]

27. Jones, H.; Cummings, C.; Nixon, H. Services in the City: Governance and Political Economy in Urban Service Delivery; Overseas Development Institute (ODI): London, UK, 2014.

28. Scott, R.E.; Ross, I.; Hawkins, P.; Blackett, I.; Smith, M.D. Diagnostics for assessing city-wide sanitation services. J. Water Sanit. Hyg. Dev. 2019, 9, 111-118. [CrossRef]

29. Cavill, S.; Sohail, M. Strengthening accountability for urban services. Environ. Urban. 2004, 16, 155-170. [CrossRef]

30. Linstone, H.A.; Turoff, M. The Delphi Method: Techniques and Applications. J. Mark. Res. 1976, 13, 317-318. [CrossRef]

31. Hsu, C.-C.; Sandford, B.A. The Delphi Technique: Making Sense of Consensus. Pract. Assess. Res. Eval. 2007, 12, 1-8.

32. Stewart, D.; Gibson-Smith, K.; MacLure, K.; Mair, A.; Alonso, A.; Codina, C.; Cittadini, A.; Fernandez-Llimos, F.; Fleming, G.; Gennimata, D.; et al. A modified Delphi study to determine the level of consensus across the European Union on the structures, processes and desired outcomes of the management of polypharmacy in older people. PLOS ONE 2017, 12, 1-17. [CrossRef] [PubMed]

33. Okoli, C.; Pawlowski, S.D. The Delphi method as a research tool: An example, design considerations and applications. Inform. Manag. 2004, 42, 15-29. [CrossRef]

34. Perveen, S.; Kamruzzaman, M.; Yigitcanlar, T. Developing policy scenarios for sustainable urban growth management: A Delphi approach. Sustainability 2017, 9, 1787. [CrossRef] 
35. Hasson, F.; Keeney, S. Enhancing rigour in the Delphi technique research. Technol. Forecast. Soc. Chang. 2011, 78, 1695-1704. [CrossRef]

36. WHO. Guidelines on Sanitation and Health; World Health Organization: Geneva, Switzerland, 2018; pp. 1-220.

(C) 2019 by the authors. Licensee MDPI, Basel, Switzerland. This article is an open access article distributed under the terms and conditions of the Creative Commons Attribution (CC BY) license (http://creativecommons.org/licenses/by/4.0/). 